Check for updates

1 London School of Paediatrics

2 Department of Sociology, University of Cambridge

3 Ethox Center, University of Oxford

4 Cardiff University School of Medicine, Cardiff, UK

5 Royal Aberdeen Children's Hospital Cite this as: $B M / 2021 ; 375: n 3067$ http://dx.doi.org/10.1136/bmj.n3067 Published: 13 December 2021

\title{
Addressing racist parents in a paediatric setting: the nuance of zero tolerance policies
}

\section{Healthcare professionals need clearer guidance on responding to racism in paediatric settings, argue Zeshan Qureshi and colleagues}

\section{Zeshan Qureshi, ${ }^{1,2}$ Mehrunisha Suleman, ${ }^{3}$ Alexandra Richards, ${ }^{4}$ Julian Sheather, Hugh Bishop ${ }^{5}$}

Everyone has a right to healthcare, but on occasion this can conflict with the right of healthcare professionals to dignity in the workplace. One example is when a patient refuses the care of a healthcare professional on the grounds of race. This is an experience that many doctors from an ethnic minority background have faced: in one US study, $23 \%$ of ethnic minority doctors reported that a patient had directly refused their care due to their race. ${ }^{1}$ The Medical Workforce Race Equality Standard in the UK also reported that $34.4 \%$ of doctors in training from an ethnic minority background had experienced "bullying or abuse from patients, relatives, or the public" in the past year, including racist abuse. ${ }^{2}$

When an adult seeks care for themselves, it can be argued that although access to healthcare is a right, it comes with responsibilities. If these are breached by imposing racial conditionality on receiving care, healthcare professionals and organisations can refuse to treat them, as recently stated by the UK government and other professional bodies. 34 Exceptions may apply for people who are critically unwell or those with a cognitive disorder, but otherwise the importance of respecting staff dignity is imperative.

Despite this mandate, there are nuanced questions that remain unanswered. What should be done, for example, when a parent imposes racial conditionality on care for their child? Children are not morally complicit in their parents' actions, so why should their care be compromised?

The NHS lacks clear protocols for responding to and reporting racism in paediatric settings, particularly when it can compromise care. We look at how the rights of staff, parents, and children can conflict with each other when parents impose racial conditionality on the care provider for their children and suggest the key principles that healthcare professionals and organisations should follow in response.

\section{Rights of the child}

Challenging racist behaviour must not hinder a child's access to healthcare, which is paramount. In the case of a well child, where any necessary emergency care has been delivered, parental presence is less easy to justify as being in the child's best interest. Abuse can be more directly challenged and ongoing parental presence should be conditional on respectful behaviour.

Standing up to racism benefits the child in the form of positive role modelling. A child's understanding of race is influenced by their experiences throughout development and healthcare encounters can be an opportunity to challenge racist narratives that children may have been exposed to previously. ${ }^{5}$

Paediatricians also have a professional obligation to consider all child protection issues. Given its negative effects on children, extreme, overt racist behaviour, particularly when associated with violence and aggression, may give rise to such concerns. A parent or guardian that denies their child access to medical treatment based on the ethnicity of the available healthcare professional may meet UK and other legal definitions of committing neglect. ${ }^{6} 7$

However, there may be occasions where a parent's racism is less explicit or definable, for example, demanding a doctor who speaks better English, making it harder to label as a child protection issue. And, even if a parent explicitly has a racial preference, if they are still able to privately arrange timely and appropriate assessments so that their child's health is not compromised, it would not constitute neglect. That said, any racism is morally unacceptable and being around racist individuals - termed vicarious racism-may have other negative impacts on children. ${ }^{89}$

\section{Rights of parents}

Those with parental responsibilities have a legal and moral right to, as far as possible, independently raise their children and have access to competent doctors. Children, particularly when young, are often dependent on their parents for physical and psychological support and also as proxy decision makers if they lack legal competence. Parental permission is often required for medical interventions and some parental decisions may be permitted even if they clash with doctors' preferences. Parents may, for example, reject medically established but non-urgent treatments, like childhood immunisations, and may briefly delay non-urgent appointments for their children to accommodate their own needs.

However, such parental rights have limits. The best interests of the child are paramount, and a parent cannot make healthcare decisions for their child in the same way as they would for themselves. Parents don't have the right to insist on care that is not medically indicated, care that would result in overall harm, or care that would prolong the suffering of a child unnecessarily. Healthcare professionals owe a duty of care to the child, not to the parents.

Parents also don't have the right to impose conditions on care, which, if honoured, would be inherently 
unjust. They cannot insist, for example, that their child's care is prioritised over that of another child with a greater clinical need. Parental demands could also be unjust if they result in harm to third parties, like undermining the rights of healthcare staff.

\section{Rights of healthcare staff}

Ensuring that all healthcare professionals are treated with dignity is essential. ${ }^{1011}$ Racism is associated with numerous negative health outcomes for staff, including poorer mental health. ${ }^{12-14}$ Staff must be protected from danger, which includes both physical and verbal abuse. In the UK, numerous laws cover violence in the workplace and crimes motivated by racial hostility come under the definition of "hate crime." ${ }^{1516}$ It is a moral and legal obligation for healthcare organisations to report any of these incidents appropriately, which can be done alongside the delivery of medical care to a child.

Behavioural agreements, delayed appointments pending resolution, police investigation, and a hospital ban for the parent are all appropriate responses to racism from parents, depending on their behaviour. These don't necessarily compromise care or stop parental involvement in decision making, but instead they protect staff and uphold core organisational and societal values of zero tolerance to racism.

It follows from this right to dignity that staff preferences for their personal involvement in a consultation with racist parents must be central to decisions about ongoing care. Yet even if a healthcare professional wants to continue with a consultation, and the family acquiesce once they are told that their racism is unacceptable, that staff member is still in a more vulnerable position. They may be at risk of further aggression or disproportionate scrutiny of their medical competence. ${ }^{17}$ In such circumstances, sensitive senior support, the presence of chaperones or security, and comprehensive documentation are vital. However, if the risk to staff cannot be sufficiently minimised and a child needs immediate care, this may mean that it is in the doctor's best interest to be replaced if it can be facilitated. This is not primarily acceding to the parental request; it is ensuring that staff are appropriately protected.

\section{A way forward}

Responding to racism from a child's parents should involve balancing three factors: presence of abuse, the rights of the healthcare provider, and urgency of intervention for the child. ${ }^{18}$

Staff safety should be considered at the outset. Parents expressing dissatisfaction through aggressive verbal or physical acts is always inappropriate and puts a barrier in place for a child's access to care. It undermines both the right for staff to be treated with respect and their need for physical safety. Abuse ought to be immediately de-escalated, with security support if needed. If the child is stable, abused staff members must have no obligation to continue such consultations and treatment may be delayed while seeking resolution. Staff also have a right to be protected from repeat abuse, meaning behavioural agreements and parental bans should be considered.

In a case where a child requires urgent medical attention, however, this must take priority. Protecting the health of a severely unwell child may require temporary accommodation of a parent's racist preferences. Imagine, for example, a breathless child, clinging to their mother who is demanding a white doctor. Although this is fundamentally unjust, the distress of the child is profound and may be exacerbated by removing the parent. Using a model that looks to the best interests of the child, and in the absence of realistic alternatives, re-allocating the child to a doctor in line with the mother's racial preferences could be justified as a way to minimise the child's distress and facilitate emergency care. However, this must not imply that parents have a right to make such a claim nor that healthcare professionals have a duty to fulfil it. It is simply that, on this occasion, the vital health interests of the child must take priority. Such acute management must, however, be accompanied by short and long term action to protect staff, including appropriate sanctions against racist parents, team debriefs, and psychological support for healthcare staff.

\section{Standing up to racism}

Racism is never acceptable. Organisational leadership is key to eradicate and challenge racism in healthcare, with clear anti-racist guidelines on the management of racist parents necessary for this. Healthcare institutions, employers, medical regulators, and paediatric colleges would benefit greatly from clarifying such policies to empower all their staff to stand up to racism and support those who have been affected.

Acknowledgments: We would like to thank Andrew Tagg, Mala Rao, Elizabeth Wortley, lan Sinha, Adam Lawton, Olivia Misquitta, Nisha Pargrass, and the RCPCH EDI member reference group for giving feedback on early drafts of this work.

\section{Competing interests: We have read and understood BMJ policy on declaration of interests.}

Julian Sheather has the following interests to declare: I am employed part time as a specialist adviser in ethics and human rights by the British Medical Association. I am employed on an ongoing ethics consultancy basis with Medecins Sans Frontieres for which I occasionally receive travel and hospitality to attend overseas conferences and provide ethics advice and consultancy services. I am a member of the Institute of Medical Ethics. I am occasionally paid to offer ethics talks to medical students and doctors in training. This can include ordinary travel and accommodation, largely within the UK.

Zeshan Qureshi has the following interests to declare: I am a member of the RCPCH EDI member reference group.

Hugh Bishop has the following interests to declare: I am a member of the RCPCH EDI member reference group.

Provenance and peer review: Not commissioned; peer reviewed.

Serafini K, Coyer C, Brown Speights J, etal. Racism as Experienced by Physicians of Color in the Health Care Setting. Fam Med 2020;52:282-7.

doi: 10.22454/FamMed.2020.384384. pmid: 32267524

2 Medical Workforce Race Equality Standard (MWRES): WRES indicators for the medical workforce 2020. NHS England. July 2021.

3 MDU. Dealing with racism from patients. The MDU. 14 July 2021 [Available from: https://www.themdu.com/guidance-and-advice/guides/dealing-with-racism-from-patients. Rimmer A. Don't accept racist abuse, Hancock tells NHS staff. BMJ 2019;367:16425. doi: 10.1136/bmj.16425. pmid: 31699785

Matthew AJ, Clark MA, McDavid LM. Combating racism: the role of the pediatrician. Pediatr Res 2021;90:708-10. doi: 10.1038/s41390-020-01345-x. pmid: 33469175

6 Children and Young Persons Act. InGovernment U, ed. UK Public General Acts 1933 c. 12 (Regnal. 23_and_24_Geo_5). Part I Offences, 1933.

Children Act. In: Government U, ed. UK Public General Acts 1989 c. 41 SCHEDULE 2 Part I. 1989.

8 Heard-Garris NJ, Cale M, Camaj L, Hamati MC, Dominguez TP. Transmitting Trauma: A systematic review of vicarious racism and child health. Soc Sci Med 2018;199:230-40. doi: 10.1016/..socscimed.2017.04.018. pmid: 28456418

9 Trent M, Dooley DG, Dougé JSECTION ON ADOLESCENT HEALTHCOUNCIL ON COMMUNITY PEDIATRICSCOMMITTEE ON ADOLESCENCE. The Impact of Racism on Child and Adolescent Health. Pediatrics 2019;144:e20191765. doi: 10.1542/peds.2019-1765. pmid: 31358665

10 Koschmann KS, Jeffers NK, Heidari O. "I can’t breathe": A call for antiracist nursing practice. Nurs Outlook 2020;68:539-41. doi: 10.1016/j.outlook.2020.07.004. pmid: 32811661

11 Garran AM, Rasmussen BM. How Should Organizations Respond to Racism Against Health Care Workers?AMA J Ethics 2019;21:E499-504. doi: 10.1001/amajethics.2019.499. pmid: 31204990

12 Paradies Y, Ben J, Denson N, etal. Racism as a Determinant of Health: A Systematic Review and Meta-Analysis. PLoS One 2015;10:e0138511-11.

doi: 10.1371/journal.pone.0138511. pmid: 26398658

13 Mollica RF, Fernando D. When racial trauma is a chief complaint among health-care staff. Lancet 2020;396:e84. doi: 10.1016/S0140-6736(20)32223-6. pmid: 33125928

14 Gil-González D, Vives-Cases C, Borrell C, etal. Racism, other discriminations and effects on health. J Immigr Minor Health 2014;16:301-9. doi: 10.1007/s10903-012-9743-y. pmid: 23104225

15 Health and Safety at Work Act. InGovernment U, ed. UK Public General Acts 1974 C. 37. 1974.

16 Equality Act. In: Government U, ed. UK Public General Acts2010 c. 15. 2010. 
17 Bamrah JS, Mehta R, Everington S, et al. Racism and the General Medical Council. BM) Opinion. 29 June 2021. https://blogs.bmj.com/bmi/2021/06/29/racism-and-the-general-medical-council/

18 Qureshi Z, Suleman M, Richards A, Sheather J, Bishop H. How should we deal with racist carers? Don't Forget the Bubbles, 2021. 